\section{New radon cancer hazard study no cause for alarm in Britain}

\section{London}

MORE than 20,000 homes in the southwest of England are to be the subject of a major health study to determine how cancers caused by the emission of radon gas from their foundations can be prevented.

Radon-222, a naturally occurring radioactive gas emitted from igneous rock with uranium content such as granite, can easily be dispersed in the open air, but in the long term produces lung cancers among those living on it. Radon risks have recently been an issue in the Appalachians.

The government initiative is the result of recommendations made to the Department of the Environment by the National Radiological Protection Board (NRPB) which has studied the danger in the southwest of England, the Pennines and the highlands of Scotland. A two-year research programme on remedial and preventive measures is to be undertaken by the Building Research Establishment.

NRPB, which has previously studied the problem in mines, has recently completed a survey of 3,000 dwellings across the United Kingdom. The measurements were taken "in more detail in those areas where high concentrations would be expected to occur". The board is cautious about the dangers; it claims that "there is no direct evidence that this [lung cancer] occurs in the home, but the risk may be estimated from health studies of miners who were exposed at work".

Cornwall and Devon are the two most

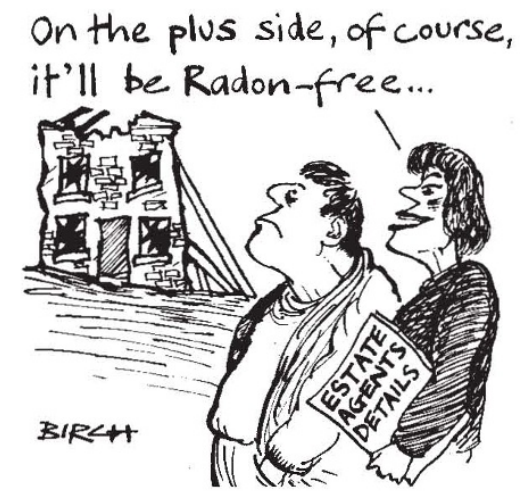

vulnerable counties in the United Kingdom although the incidence of lung cancer there is lower than in many other parts of the country, mainly large conurbations.

The NRPB survey estimated that the occupants of 20,000 homes are exposed to an unacceptably high concentration of the gas - 20 millisieverts per year. Another 2,000 homes are thought to have concentrations of two and a half times that dosage.

The lower limit is defined by the protection board as the 'action level' at which simple remedies must be implemented to reduce the level of exposure; the higher levels require immediate and "severe action". New dwellings, the board recommends, should be built to a specification that will limit such radon exposure to 5 millisieverts a year.

NRPB does not believe it is being alarmist. Apart from its studies among miners, the epidemiological evidence on lung cancer incidents among underground workers, amassed over the past 35 years, supports its view. The evidence is overwhelming from uranium miners in Colorado, Bohemia, Canada and Sweden.

Using these data, it is easy to "estimate

\section{Washington}

A ClOud of $1.0 \mathrm{~km}^{3}$ of carbon dioxide gas released from Lake Nyos in Cameroon last August caused the deaths by asphyxiation of at least 1,700 people, according to a report prepared by a US scientific team that investigated the natural disaster. The US report agrees substantially with that of a UK team published earlier this year (see Nature 325, 105; 1987), but a key difference in what caused the gas release may determine whether simple measures can prevent similar disasters.

The US Agency for International Development sponsored the US investigation. A ten-member scientific team, drawn from universities and government laboratories, visited Cameroon in early September. Although the lake still contained large amounts of dissolved $\mathrm{CO}_{2}$, the US team could find no evidence of excess sulphur or chlorine compounds that would be expected to accompany a large, rapid input of volcanic gas.

The team also failed to detect warming of water at the lake bottom that might reasonably accompany volcanic activity. Instead, they conclude that the $\mathrm{CO}_{2}$ entered the lake slowly, and had a magmatic origin. Released deep in the Earth's crust, the gas lost its reactive components such as sulphur and chlorine compounds before it reached the surface. A biogenic origin for the gas is ruled out by measurements of carbon-14, the stable carbon-isotope composition of $\mathrm{CO}_{2}$ and helium isotopes.

The US report concludes that water density differences kept the water charged with $\mathrm{CO}_{2}$ on the bottom of Lake Nyos until something disturbed it. Edward Koenigsberg, leader of the US team, says a variety of events could have triggered the upwelling of $\mathrm{CO}_{2}$-rich waters. Among the triggers mentioned are some seismic

the risk from exposure to radon in the home over a lifetime".

The best estimate is a 2 per cent risk of dying early from lung cancer through lifetime household exposure to a dose of 20 millisieverts a year. DOE is at pains to prevent panic. Environment minister William Waldegrave claimed: "I want to stress that the risks from radon are assessed in terms of life-time exposure. There is therefore no need for drastic immediate measures to reduce levels. It is a matter of record that, in Devon and Cornwall, where radon levels tend to be higher than average, the death rate from lung cancer is lower than in many other parts of the country. The first step is to obtain an accurate measurement of the situation, so that the need for any remedial measures can be properly assessed."

Bill Johnstone

\title{
Cameroon lake gas disaster a lesson for the future
}

event, a small rockslide from the cliffs on the lakeside or even a storm that took place earlier on the day of the disaster.

Koenigsberg says the lakes in the region are at their most unstable in August, when temperature differences between surface and bottom waters are the smallest.

Pathology reports are consistent with the $\mathrm{CO}_{2}$ cloud explanation for the disaster. Survivors reported that victims appeared to die without a struggle. Investigations revealed no evidence for $\mathrm{H}_{2} \mathrm{~S}$ gas, although many reported smelling rotten eggs or gunpowder. The team concluded that these were olfactory hallucinations, previously reported to follow acute exposure to $\mathrm{CO}_{2}$.

S.J. Freeth, one of the three-man British team, is sceptical about the hallucination explanation. Freeth agrees with the US report's theory of the origin of the gas, but concludes that the event was triggered by a pulse of gas coming up through a volcanic vent in the north-east corner of the lake. Such an injection of $\mathrm{CO}_{2}$ would still possess enough $\mathrm{H}_{2} \mathrm{~S}$ and $\mathrm{SO}_{2}$ to make their characteristic odours detectable.

A large amount of $\mathrm{CO}_{2}$ remains dissolved in Lake Nyos, and the possibility of another fatal release remains. If the slowrelease theory for the build up of $\mathrm{CO}_{2}$ is correct, the most practical way to reduce the gas content of the lake in a controlled fashion would be to pipe water from the bottom to the surface. The US team reckons $\mathrm{CO}_{2}$ expansion from the upward movement of water will create sufficient lift to propel the water upward without external pumping. A $9.5-\mathrm{cm}$ pipe would completely 'treat' the lake in three years. But Koenigsberg says that if the pulse injection theory is accurate, such simple measures for reducing the danger will be to no avail. 